\begin{tabular}{|c|c|}
\hline Title & $\begin{array}{l}\text { Mechanochromic Switching between Delayed Fluorescence and Phosphorescence of Luminescent Coordination } \\
\text { Polymers Composed of Dinuclear Copper(I) Iodide Rhombic Cores }\end{array}$ \\
\hline Author(s) & Kobay ashi, A tsushi; Y oshida, Y uya; Y oshida, Masaki; Kato, Masako \\
\hline Citation & $\begin{array}{l}\text { Chemistry-A European journal, 24(55), } 14750-14759 \\
\text { https://doi.org/10.1002/chem.201802532 }\end{array}$ \\
\hline Issue Date & $2018-10-01$ \\
\hline Doc URL & http:/hdl.handle.net/2115/75620 \\
\hline Rights & $\begin{array}{l}\text { This is the peer-reviewed version of the following article: Chemistry-A European journal, V olume24, Issue55, October } \\
\text { 1, } 2018 \text {, Pages } 14750-14759 \text {, which has been published in final form at https://doi.org/10.1002/chem.201802532. This } \\
\text { article may be used for non-commercial purposes in accordance with W iley-V CH Terms and Conditions for Self- } \\
\text { A rchiving. }\end{array}$ \\
\hline Tyре & article (author version) \\
\hline File Information & Y oshida Mechanochromic-Cu2-polymer-ver14_1.pdf \\
\hline
\end{tabular}

Instructions for use 


\section{Mechanochromic Switching between Delayed Fluorescence and Phosphorescence of Luminescent Coordination Polymers Composed of Dinuclear Copper(I) lodide Rhombic Cores}

\begin{abstract}
The synthesis and photophysical properties of two luminescent $\mathrm{Cu}(\mathrm{I})$ coordination polymers, $\left[\mathrm{Cu}_{2} \mathrm{I}_{2}\left(\mathrm{PPh}_{3}\right)_{2}(3-\mathrm{tpyb})\right]_{n}$ and $\left[\mathrm{Cu}_{2} \mathrm{l}_{2}\left(\mathrm{PPh}_{3}\right)_{2}(4-\mathrm{tpyb})\right]_{\mathrm{n}}$ (Cu-3-tpyb and Cu-4-tpyb; $\mathrm{PPh}_{3}=$ triphenylphosphine, $m$-tpyb $=1,3,5$-tris $(m$-pyridyl)benzene $(m=3$, $4)$ ), are described. X-ray structural analysis indicated that onedimensional coordination chains comprising rhombic $\left\{\mathrm{Cu}_{2} \mathrm{I}_{2}\left(\mathrm{PPh}_{3}\right)_{2}\right\}$ cores and $m$-tpyb bridging ligands were formed. Both Cu-3-tpyb and Cu-4-tpyb exhibited blue-to-yellow thermally activated delayed fluorescence (TADF) that originated from mixing of the metal-toligand and halide-to-ligand charge-transfer excited states and moderate emission quantum yields of 0.29 and 0.27 , respectively, at 298 K. Further, mechanochromic luminescence was observed for both complexes. The emission lifetimes indicated that the origin of emission switched from TADF to phosphorescence, which was derived from the triplet cluster-centred $\left({ }^{3} \mathrm{CC}\right)$ emissive state generated by grinding-induced amorphization.
\end{abstract}

Atsushi Kobayashi, ${ }^{*[a]}$ Yuya Yoshida, ${ }^{[a]}$ Masaki Yoshida, ${ }^{[a]}$ and Masako Kato*[a]

\section{Introduction}

Luminescent $\mathrm{Cu}(\mathrm{I})$ complexes have attracted considerable attention as promising alternative materials to luminescent noble metal complexes because of their characteristic $\mathrm{d}^{10}$ electronic configuration that eliminates the non-radiative decay pathway from the $d-d$ excited state. ${ }^{1-7}$ Recent extensive studies of luminescent $\mathrm{Cu}(\mathrm{l})$ complexes have led to the achievement of interesting photophysical properties such as extremely bright emission with $\sim 100 \%$ quantum yield, ${ }^{8-9}$ thermally activated delayed fluorescence (TADF), ${ }^{10-16}$ and external-stimuli responsive luminescence. ${ }^{17-28}$ One of the characteristic features of luminescent $\mathrm{Cu}(\mathrm{I})$ complexes is that various emissive states can contribute to their luminescence. The metal-to-ligand charge-transfer (MLCT) excited state is a well-known emissive state of not only $\mathrm{Cu}(\mathrm{I})$ complexes but also of other noble metal complexes such as those of $\mathrm{Ru}(\mathrm{II}), \mathrm{Ir}(\mathrm{III})$, and $\mathrm{Pt}(\mathrm{II}) .{ }^{29-30}$ It is well known that in order for the $\mathrm{Cu}(\mathrm{I})$ complex to achieve high emission quantum yield, the Jahn-Teller flattening distortion of the MLCT excited state should be suppressed. ${ }^{31-38}$ The wide emission color tuning ranging from blue to red has been also achieved by the modification of the $\pi^{\star}$ orbitals of the organic ligands. ${ }^{39-41}$ Since the photoexcited electron and the remaining hole are spatially separated in the $\pi^{\star}$ orbital of the organic ligand and the $3 d$ orbital of the $\mathrm{Cu}(\mathrm{I})$ ion, the energy gap between the

a] Dr. A. Kobayashi, Mr. Y. Yoshida, Dr. M. Yoshida, and Prof. M. Kato.

Department of Chemistry, Faculty of Science, Hokkaido University

North-10 West-8, Kita-ku, Sapporo 060-0810, Japan

E-mail:akoba@sci.hokudai.ac.jp (Dr. A. Kobayashi) mkato@sci.hokudai.ac.jp (Prof. M. Kato)

Supporting information for this article is given via a link at the end of the document. single and triplet MLCT excited states tends to be small enough to permit an inverted intersystem crossing from the stable $T_{1}$ to relatively unstable $S_{1}$ state, resulting in TADF. ${ }^{10-16}$ One of the other typical emissive states is the triplet cluster-centered $\left({ }^{3} \mathrm{CC}\right)$ excited state that is usually observed for the iodide-bridged $\mathrm{Cu}(\mathrm{I})$ cluster complexes. ${ }^{42-45}$ An interesting feature is the externalstimuli responsive luminescence such as thermochromic, vapochromic, and mechanochromic luminescence that may be applicable to various types of sensors. ${ }^{17-28}$ For example, interesting thermochromic luminescence has been observed for cubane-type $\mathrm{Cu}(\mathrm{l})$ cluster complexes $\left[\mathrm{Cu}_{4} \mathrm{I}_{4}(\mathrm{py})_{4}\right]$ and $\left[\mathrm{Cu}_{4} \mathrm{l}_{4}\left(\mathrm{PPh}_{3}\right)_{4}\right]$ (py = pyridine, $\mathrm{PPh}_{3}=$ triphenylphosphine $) .{ }^{18,20}$ Furthermore, mechanochromic luminescence has been reported for a similar cubane-type cluster complex, $\left[\mathrm{Cu}_{4} \mathrm{I}_{4}\left(\mathrm{PPh}_{2}\left(\mathrm{CH}_{2} \mathrm{CH}=\mathrm{CH}_{2}\right)\right)_{4}\right]$, which has a slightly modified phosphine ligand. ${ }^{21}$ An interesting phenomenon was recently reported by Farinella et al.; the coordination polymer $\left[\mathrm{Cu}_{2} \mathrm{I}_{2}(3-\right.$ pica) $]_{n}$ (3-pica $=3$-picolylamine) comprising the iodide-bridged rhombic $\left\{\mathrm{Cu}_{2} \mathrm{I}_{2}\right\}$ dinuclear cores and 3-pica linkers exhibited interesting thermochromic switching between TADF that was derived from the $\mathrm{CT}$ excited state and the phosphorescence originating from the ${ }^{3} \mathrm{CC}$ state. ${ }^{27}$ However, the creation of such switching of the emission origins in the chromic behaviors in response to other external stimuli (e.g. vapors, mechanical grinding) is still a challenging research subject.

Recently, we have focused on the development of smart sensing functions based on the strongly emissive $\mathrm{Cu}(\mathrm{I})$ complexes. In this work, to switch the emission origin in the vapochromic and/or mechanochromic behavior, two different types of organic ligands were selected. One of these ligands is 1,3,5-tris( $m$-pyridyl)benzene (Scheme $1 ; m$-tpyb, $m=3,4$ ), ${ }^{46,47}$ which can adopt various coordination modes

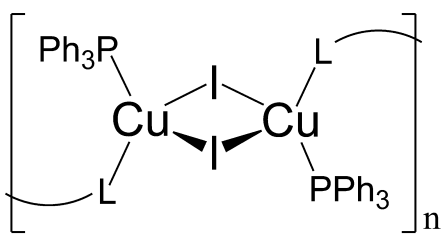

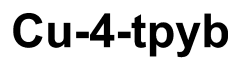
Cu-3-tpyb

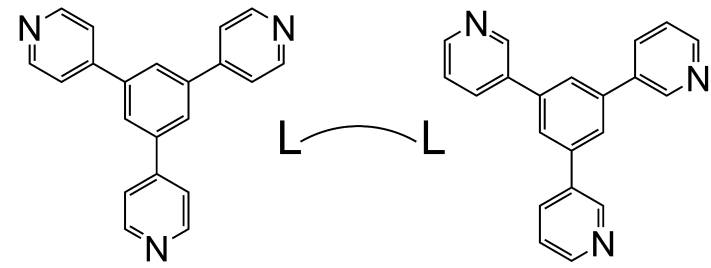

Scheme 1. Schematic molecular structures of coordination polymers, Cu-4tpyb and Cu-3-tpyb. 
to bridge several $\mathrm{Cu}(\mathrm{I})$ ions based on the three pyridinyl $\mathrm{N}$ atoms. The other ligand is $\mathrm{PPh}_{3}$, which is used to construct a sterically bulky coordination environment around the $\mathrm{Cu}(\mathrm{I})$ ion. Herein, the synthesis, crystal structures, and photophysical properties of the newly synthesized luminescent $\mathrm{Cu}(\mathrm{I})$ coordination polymers, $\left[\mathrm{Cu}_{2} \mathrm{I}_{2}\left(\mathrm{PPh}_{3}\right)_{2}(m \text {-tpyb) }]_{\mathrm{n}}(m=3,4\right.$; hereafter $\mathrm{Cu}$-m-tpyb), have been described. Furthermore, it has been demonstrated that both Cu-m-tpyb exhibited strong TADF with CT character and an interesting mechanochromic behavior involving the switching of the emission origin from TADF to ${ }^{3} \mathrm{CC}$ phosphorescence from the impurity sites generated during the grinding-induced amorphization.

\section{Results and Discussion}

\section{Crystal structures}

Figure 1 shows the crystal structure of Cu-4-tpyb. Crystallographic data and the selected bond lengths and angles are listed in Tables S1 and S2. Cu-4-tpyb consisted of two crystallographically independent $\mathrm{Cu}$ ions, two iodide anions, two $\mathrm{PPh}_{3}$ ligands, and a 4-tpyb bridging ligand. Each $\mathrm{Cu}$ ion adopted a typical tetrahedral coordination geometry for $\mathrm{Cu}(\mathrm{I})$ ion, where the $\mathrm{Cu}^{+}$ion was surrounded by two $\mathrm{I}^{-}$ions, the $\mathrm{P}$ atom of $\mathrm{PPh}_{3}$, and the $\mathrm{N}$ atom of 4-tpyb. The two $\mathrm{Cu}^{+}$ions were bridged by two $\mathrm{I}^{-}$ions to form a $\left\{\mathrm{Cu}_{2} \mathrm{I}_{2}\right\}$ rhombic core. The $\mathrm{Cu}-\mathrm{N}$ bond distances in Cu-4-tpyb ranged from 2.071(8) to 2.081(8) $\AA$ and the two $\mathrm{Cu}-\mathrm{P}$ bond distances were 2.218(3) $\AA$. These distances were comparable to the other halide-bridged $\mathrm{Cu}(\mathrm{I})$ complexes with $\mathrm{N}$ heteroaromatic ligands and $\mathrm{PPh}_{3} .{ }^{39}$ The $\mathrm{Cu}$... Cu distance in the $\left\{\mathrm{Cu}_{2} \mathrm{I}_{2}\right\}$ core (3.302(2) $\AA$ ) was longer than the sum of the van der Waals radii of $\mathrm{Cu}(2.8 \AA)$ and indicated negligible metallophilic interactions. Two of the three $\mathrm{N}$ atoms of the 4-tpyb ligand were coordinated to two different $\left\{\mathrm{Cu}_{2} \mathrm{I}_{2}\right\}$ cores to form a spiral onedimensional (1-D) chain structure along the a axis (see Figure 1a). The non-coordinating $N$ atom of 4-tpyb ligand could form a weak hydrogen bond with the $\mathrm{H}$ atom of the central benzene ring of the 4-tpyb ligand of the adjacent 1-D chain, which connected the 1-D chains along the $b$ axis $(\mathrm{C}-\mathrm{H} \cdots \mathrm{N}=3.605 \AA$, Figure $\mathrm{S} 1)$. As shown in Figure $1 \mathrm{~b}$, there were four porous channels in one unit cell along the $b$ axis in which two $\mathrm{CHCl}_{3}$ and $\mathrm{H}_{2} \mathrm{O}$ molecule were adsorbed. The diameter and void fraction were estimated to be $5.8 \AA \times 8.5 \AA$ and $20 \%$, respectively. There were no remarkable interactions between the adsorbed solvent molecules and the coordination-polymer framework.

The crystal structure of Cu-3-tpyb is depicted in Figure 2. A similar 1-D chain structure to that of Cu-4-tpyb was also confirmed in Cu-3-tpyb, wherein the 3-tpyb ligands bridged the rhombic dinuclear cores along the $c$ axis (Figure 2a). The $\mathrm{Cu}-\mathrm{N}$ and $\mathrm{Cu}-\mathrm{P}$ bonds distances were similar to those of $\mathrm{Cu}$-4-tpyb (Table S2). A noticeable difference between these Cu-m-tpyb coordination polymers is the number of crystallographically independent dinuclear cores in the unit cell; two independent cores were found in Cu-3-tpyb. The $\mathrm{Cu}$... Cu distance in the $\left\{\mathrm{Cu}(1)_{2}-\mathrm{I}(1)_{2}\right\}$ core $(2.9530(7) \AA)$ was shorter by about $0.4 \AA$ than the that in the $\left\{\mathrm{Cu}(2)_{2}-\mathrm{I}(2)_{2}\right\}$ core $(3.3569(7) \AA)$. However,
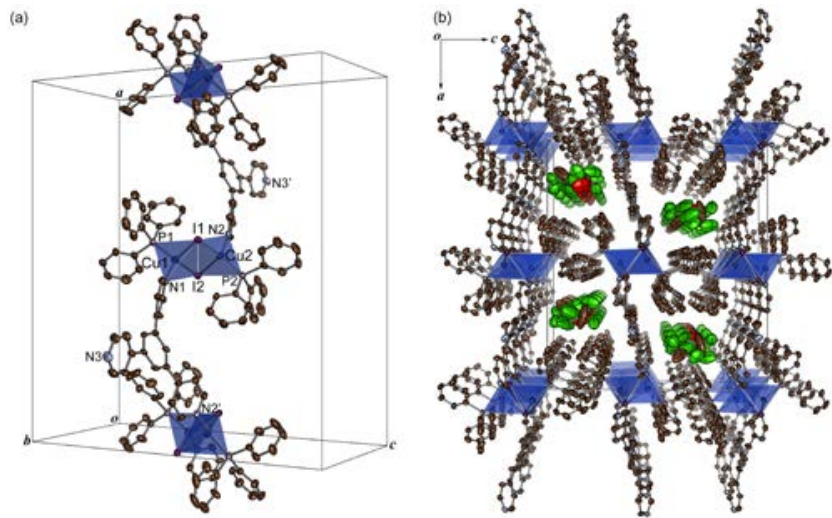

Figure 1. Crystal structure of Cu-4-tpyb. (a) 1-D coordination chain structure and (b) packing diagram viewed along the $b$ axis. Coordination spheres of $\mathrm{Cu}(\mathrm{I})$ ions are shown as blue tetrahedrons. Brown, light blue, red, green, and purple ellipsoids represent $\mathrm{C}, \mathrm{N}, \mathrm{O}, \mathrm{Cl}$, and I atoms, respectively. All $\mathrm{H}$ atoms are omitted for clarity.
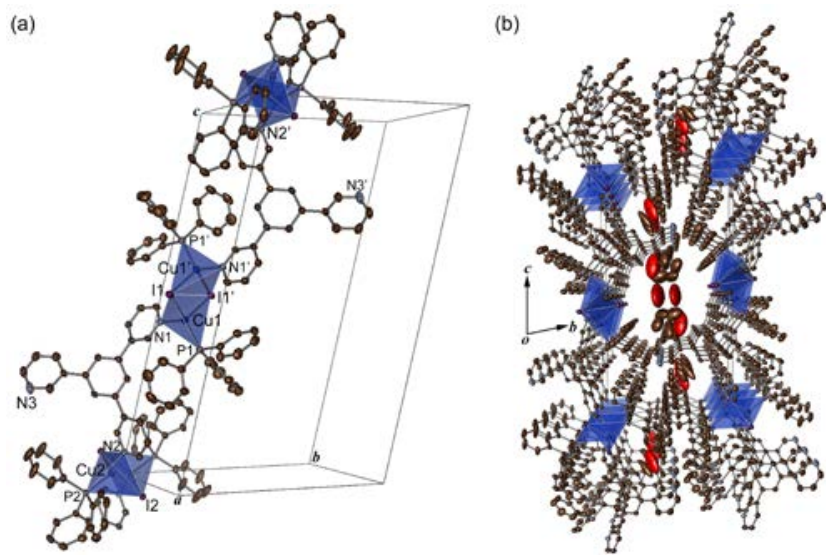

Figure 2. Crystal structure of Cu-3-tpyb. (a) 1-D coordination chain structure and (b) packing diagram viewed along the a axis. Coordination spheres of $\mathrm{Cu}(\mathrm{I})$ ions are shown as blue tetrahedrons. Brown, light blue, red, and purple ellipsoids represent $\mathrm{C}, \mathrm{N}, \mathrm{O}$, and I atoms, respectively. All $\mathrm{H}$ atoms are omitted for clarity.

both distances were longer than the sum of the van der Waals radii of $\mathrm{Cu}(2.8 \AA)$, and the metallophilic interactions in these dinuclear cores were also negligible. Similar to the 4-tpyb ligands of Cu-4-tpyb, two of the three $\mathrm{N}$ atoms of the 3-tpyb ligand were coordinated to the $\mathrm{Cu}^{+}$ions and the remaining one formed a weak hydrogen bond with the $\mathrm{H}$ atom of one of the phenyl rings of $\mathrm{PPh}_{3}$ of the adjacent 1-D chain $(\mathrm{C}-\mathrm{H} \cdots \mathrm{N}=3.320$ $\AA$ ). There were two different porous channels along the $a$ axis as shown in Figure 2b. One THF and one water molecule per $\left\{\mathrm{Cu}_{2} \mathrm{I}_{2}\right\}$ core were found in the larger pore channel, which had a diameter of $6.7 \AA \times 6.9 \AA$. In the smaller pore with the diameter $5.8 \AA \times 3.6 \AA$, only one THF molecule per one $\left\{\mathrm{Cu}_{2} \mathrm{I}_{2}\right\}$ core was found (Figure $2 \mathrm{~b}$ ). As a result, a slightly larger accessible void ( $\sim 27 \%$ in the unit cell) than Cu-4-tpyb was formed. There were no significant interactions between the solvent molecules in the pores and the porous framework as in the case of Cu-4-tpyb. 


\section{Photophysical properties}

Figures 3(a) and 3(b) show the emission spectra of solid-state Cu-4-tpyb and Cu-3-tpyb at 298 and $78 \mathrm{~K}$. The purity of each sample was checked by powder X-ray diffraction (PXRD) patterns and elemental analysis (see Figure $\mathrm{S} 2$ and experimental section). Cu-4-tpyb exhibited a broad emission band centered at $545 \mathrm{~nm}$ at $298 \mathrm{~K}$ and this band was shifted to longer wavelengths by up to $570 \mathrm{~nm}$ when the temperature was reduced to $78 \mathrm{~K}$. A similar broad emission band at $498 \mathrm{~nm}$ was observed for Cu-3-tpyb at $298 \mathrm{~K}$, while the emission spectrum at $78 \mathrm{~K}$ was composed of two emission bands; one is the broad band centered at $545 \mathrm{~nm}$ and another corresponds to the higher-energy bands with vibrational progression at $442 \mathrm{~nm}$. This difference suggests that the emission origin of Cu-3-tpyb changed when the temperature was decreased. Since the isomorphous structure of Cu-3-tpyb to that of $150 \mathrm{~K}$ was clearly identified at $97 \mathrm{~K}$ (Table S1), the observed change in emission spectrum would not be due to the solid-state transition, but due
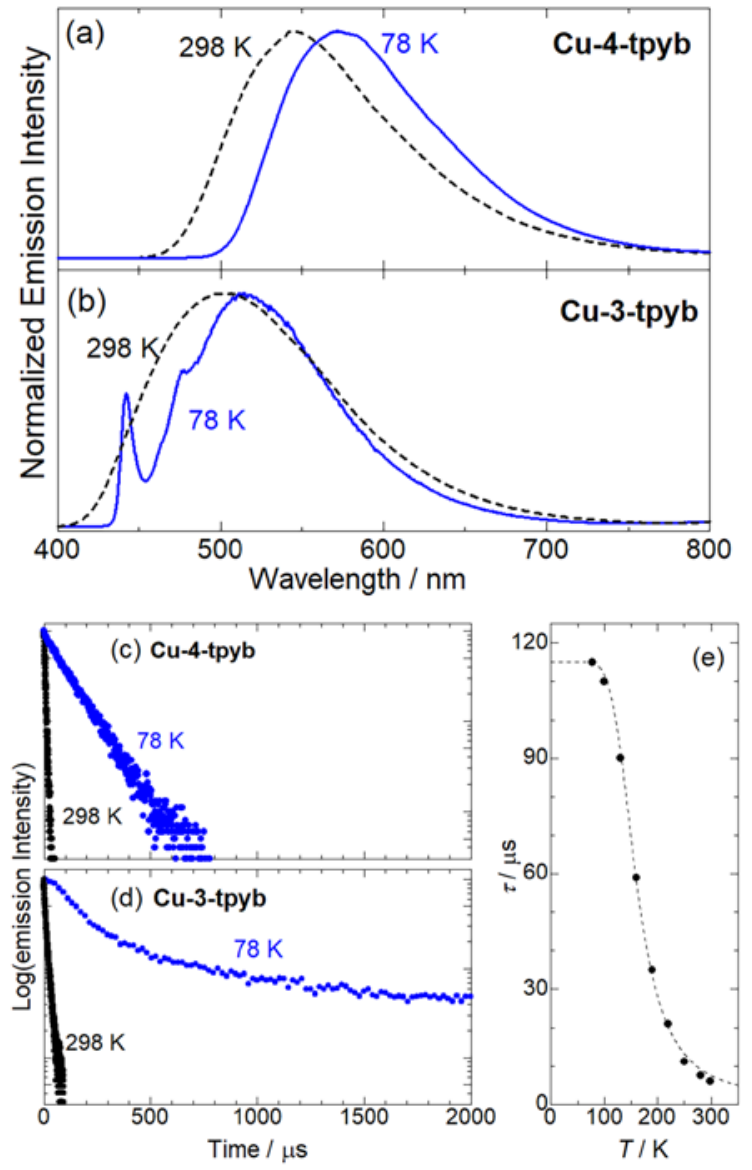

Figure 3. Temperature dependencies of the emission spectra of (a) Cu-4-tpyb and (b) Cu-3-tpyb at $298 \mathrm{~K}$ (black dotted line) and $78 \mathrm{~K}$ (blue solid line) in the solid state $\left(\lambda_{\mathrm{ex}}=350 \mathrm{~nm}\right)$. Emission decays of (c) Cu-4-tpyb and (d) Cu-3tpyb at $298 \mathrm{~K}$ (black circles) and $78 \mathrm{~K}$ (blue circles) in the solid state ( $\lambda_{\mathrm{ex}}=$ $337 \mathrm{~nm}$ ). (e) Temperature dependence of the emission lifetime of Cu-4-tpyb in the solid state. The dotted line was calculated using eq. (1).
Table 1. Luminescence properties of Cu-4-tpyb and Cu-3-tpyb in the solid states at 298 and $77 \mathrm{~K}$

\begin{tabular}{|c|c|c|c|c|c|c|c|c|}
\hline \multirow{3}{*}{$\begin{array}{c}\text { Complex } \\
\mathrm{T}(\mathrm{K})\end{array}$} & \multicolumn{4}{|c|}{ Cu-4-tpyb } & \multicolumn{4}{|c|}{ Cu-3-tpyb } \\
\hline & \multicolumn{2}{|c|}{$\begin{array}{c}\text { As } \\
\text { synthesized }\end{array}$} & \multicolumn{2}{|c|}{ Ground } & \multicolumn{2}{|c|}{$\begin{array}{c}\text { As } \\
\text { synthesized }\end{array}$} & \multicolumn{2}{|c|}{ Ground } \\
\hline & 298 & 78 & 298 & 78 & 298 & 78 & 298 & 78 \\
\hline $\begin{array}{c}\lambda_{\max }{ }^{[\mathrm{a}]} \\
(\mathrm{nm})\end{array}$ & 545 & 570 & 605 & 605 & 498 & $\begin{array}{l}442 \\
477 \\
510\end{array}$ & 553 & $\begin{array}{l}445 \\
543\end{array}$ \\
\hline$\tau(\mu \mathrm{s})$ & 6.04 & 115 & $\begin{array}{l}0.447 \\
1.340 \\
3.181\end{array}$ & $\begin{array}{c}6.28 \\
23.6 \\
108\end{array}$ & $\begin{array}{l}4.78 \\
14.47\end{array}$ & $\begin{array}{l}155 \\
625 \\
3513\end{array}$ & $\begin{array}{l}1.012, \\
3.957 \\
9.148\end{array}$ & $\begin{array}{c}49.0 \\
123 \\
690\end{array}$ \\
\hline$\tau_{\mathrm{av}}(\mu \mathrm{s})$ & - & - & 2.27 & 66.1 & 12.46 & 1879 & 6.62 & 529.9 \\
\hline$\Phi_{\mathrm{em}}$ & 0.29 & 0.84 & 0.10 & 0.36 & 0.27 & 0.73 & 0.30 & 0.67 \\
\hline $\mathrm{k}_{\mathrm{r}}\left(\mathrm{s}^{-1}\right)^{[\mathrm{b}]}$ & $\begin{array}{r}4.80 \\
\times 10^{4}\end{array}$ & $\begin{array}{l}1.11 \\
\times 10^{3}\end{array}$ & $\begin{array}{r}4.40 \\
\times 10^{4}\end{array}$ & $\begin{array}{r}5.51 \\
\times 10^{3}\end{array}$ & $\begin{array}{r}2.17 \\
\times 10^{4}\end{array}$ & $\begin{array}{l}3.88 \\
\times 10^{2}\end{array}$ & $\begin{array}{r}4.53 \\
\times 10^{4}\end{array}$ & $\begin{array}{l}1.26 \\
\times 10^{3}\end{array}$ \\
\hline $\mathrm{knr}\left(\mathrm{s}^{-1}\right)^{[c]}$ & $\begin{array}{l}1.17 \\
\times 10^{5}\end{array}$ & $\begin{array}{l}3.71 \\
\times 10^{2}\end{array}$ & $\begin{array}{c}3.96 \\
\times 10^{5}\end{array}$ & $\begin{array}{l}9.80 \\
\times 10^{3}\end{array}$ & $\begin{array}{c}5.86 \times \\
10^{4}\end{array}$ & $\begin{array}{r}1.44 \\
\times 10^{2}\end{array}$ & $\begin{array}{l}1.06 \\
\times 10^{5}\end{array}$ & $\begin{array}{l}6.23 \\
\times 10^{3}\end{array}$ \\
\hline
\end{tabular}

[a] Emission maximum. [b] Radiative rate constants, $k_{r}$, were estimated by $\Phi_{\mathrm{em}} / \tau$. [c] Nonradiative rate constants, $k_{\mathrm{nr}}$, were estimated by $k_{\mathrm{r}}\left(1-\Phi_{\mathrm{em}}\right) / \Phi_{\mathrm{em}}$.

to the change of the emission origin. The wavelength difference between the emission maxima of Cu-m-tpyb $(m=3,4)$ of $\sim 47$ $\mathrm{nm}$ suggests that the position of the coordinating $\mathrm{N}$ atoms in the tpyb ligand is an important factor for the emission energy. The similar luminescent $\mathrm{Cu}(\mathrm{I})$ coordination polymer, $\left[\mathrm{Cu}_{2} \mathrm{I}_{2}\left(\mathrm{PPh}_{3}\right)_{2}\left(4,4^{\prime}-\mathrm{bpy}\right)\right]_{\mathrm{n}}$, reportedly exhibited emission maxima at $542 \mathrm{~nm},{ }^{39}$ which is comparable to that of Cu-4-tpyb.

To elucidate the emission behaviors of Cu-m-tpyb in detail, their emission lifetimes and quantum yields were measured in the solid state at both 298 and $78 \mathrm{~K}$. The results are summarized in Table 1. As shown in Figure 3(c), a single exponential decay was observed in the emission decay curve of Cu-4-tpyb at both temperatures and the lifetime was estimated to become longer from $6.04 \mu \mathrm{s}$ at $298 \mathrm{~K}$ to $115 \mu \mathrm{s}$ at $78 \mathrm{~K}$, which are comparable values to that of $\left[\mathrm{Cu}_{2} \mathrm{I}_{2}\left(\mathrm{PPh}_{3}\right)_{2}\left(4,4^{\prime}-\mathrm{bpy}\right)\right]_{\mathrm{n}}(\tau=$ $4.0 \mu \mathrm{s}$ at $298 \mathrm{~K}, 67 \mu \mathrm{s}$ at $80 \mathrm{~K}) \cdot{ }^{39}$ Such significant increase in the emission lifetime has been previously reported for the thermally activated delayed-fluorescent (TADF) $\mathrm{Cu}(\mathrm{I})$ complexes. ${ }^{12,13,41}$ For example, Tsuboyama et al. reported that the $\mathrm{Cu}(\mathrm{I})$ dimer complex, $\quad\left[\mathrm{Cu}_{2} \mathrm{I}_{2}\right.$ (2,3-bis(diphenylphosphyno)benzene) $\left.{ }_{2}\right]$, exhibited an increase in the emission decay on the scale of two orders of magnitude from $4.0 \mu \mathrm{s}$ at $298 \mathrm{~K}$ to $211 \mu \mathrm{s}$ at $77 \mathrm{~K} .^{12} \mathrm{In}$ contrast, smaller temperature dependence of the emission lifetime has been reported for the halide-bridged $\mathrm{Cu}(\mathrm{I})$ cluster complexes, one of the typical materials showing triplet clustercentered $\left({ }^{3} \mathrm{CC}\right)$ emission. ${ }^{18,20,26}$ For example, the emission lifetimes of the cubane-type cluster complexes, $\left[\mathrm{Cu}_{4} \mathrm{l}_{4}(\mathrm{py})_{4}\right]$ and 
$\left[\mathrm{Cu}_{4} \mathrm{I}_{4}\left(\mathrm{PPh}_{3}\right)_{4}\right]$, increased by less than one order of magnitude from 11 and $4.7 \mu \mathrm{S}$ at $298 \mathrm{~K}$ to 25.5 and $26 \mu \mathrm{s}$ at $77 \mathrm{~K}$, respectively. ${ }^{18,20}$ The large temperature dependence of the emission lifetime and the broad spectral shape without vibrational progression of Cu-4-tpyb suggest that the origin of emission could be ascribed to TADF from the charge-transfer excited state. In fact, the radiative decay constant $\left(k_{\mathrm{r}}\right)$ estimated from the emission lifetime and the emission quantum yield decreased remarkably to one fiftieth upon decreasing the temperature (see Table 1).

Further investigation of the origins of emission from Cu-4-tpyb was conducted by measuring the emission lifetime at various temperatures and the results are shown in Figure 3(e). Assuming the two-state model involving the lowest excited singlet state $\left(\mathrm{S}_{1}\right)$ and the lowest excited triplet state $\left(\mathrm{T}_{1}\right)$, the observed lifetime $(\tau)$ can be expressed as a Boltzmann average by using equation (1). ${ }^{48}$

$$
\tau=\frac{3+\exp (-\Delta E / R T)}{3 / \tau_{\mathrm{T}_{1}}+1 / \tau_{\mathrm{S}_{1}} \exp (-\Delta E / R T)}
$$

where, $\Delta E$ is the energy difference between the singlet and triplet states, $\tau_{\mathrm{S} 1}$ and $\tau_{\mathrm{T} 1}$ are the lifetimes of $S_{1}$ (fluorescence) and $T_{1}$ (phosphorescence) states, respectively, $R$ is the ideal gas constant, and $T$ is the absolute temperature. The corresponding fitting result based on equation (1) for the temperature dependence of the observed emission lifetime is shown as the dotted line in Figure 3(e). The obtained $\Delta E$ value $\left(650 \mathrm{~cm}^{-1}\right)$ was comparable to the difference in the wavelengths of emission maxima at 298 and $78 \mathrm{~K}\left(805 \mathrm{~cm}^{-1}\right)$. These results clearly indicate that the emission of Cu-4-tpyb was attributable to TADF originating from the CT excited state.

As shown in Figure 3(d), a double exponential decay was observed for Cu-3-tpyb at $298 \mathrm{~K}$ and the estimated emission lifetimes were 4.78 and $14.47 \mu \mathrm{s}$. Considering that there are two crystallographically different $\left\{\mathrm{Cu}_{2} \mathrm{I}_{2}\right\}$ cores in the crystal structure of Cu-3-tpyb, these two emission components may be derived from these two different cores with the same emissive state. At $78 \mathrm{~K}$, three emission components with lifetimes of $155 \mu \mathrm{s}, 625$ $\mu \mathrm{s}$, and $3.51 \mathrm{~ms}$ were observed. These lifetimes are remarkably longer than the emission lifetime of Cu-4-tpyb, implying the contribution of a different emissive state. Since the emission band with clear vibrational progression was observed at $78 \mathrm{~K}$ (Figure 3(b)), one plausible origin is the triplet ligand-centered $\left({ }^{3} \pi-\pi\right)$ excited state. In the time-resolved emission spectra of Cu-3-tpyb at $78 \mathrm{~K}$, only the broad emission band centered at $\sim 500 \mathrm{~nm}$ was observed before $1.5 \mathrm{~ms}$, but another sharp peak at $450 \mathrm{~nm}$ that was probably derived from the ${ }^{3} \pi-\pi$ state was clearly observed over a longer time range ( $>2 \mathrm{~ms})$. Thus, the longest emission component of Cu-3-tpyb could be attributed to the ${ }^{3} \pi-\pi$ emission of the bridging 3 -tpyb ligand. The other two shorter-lived emission components were ascribed to TADF from the CT excited state like Cu-4-tpyb, because the average emission lifetimes of these two components $\left(\tau_{\mathrm{av}}=12.5\right.$ and 155 $\mu$ s at 298 and $78 \mathrm{~K}$, respectively) were comparable to that of $\mathrm{Cu}$ 4-tpyb. It is worth noting that only Cu-3-tpyb exhibited the ligand-centered ${ }^{3} \pi-\pi$ emission, which was because of its higher-

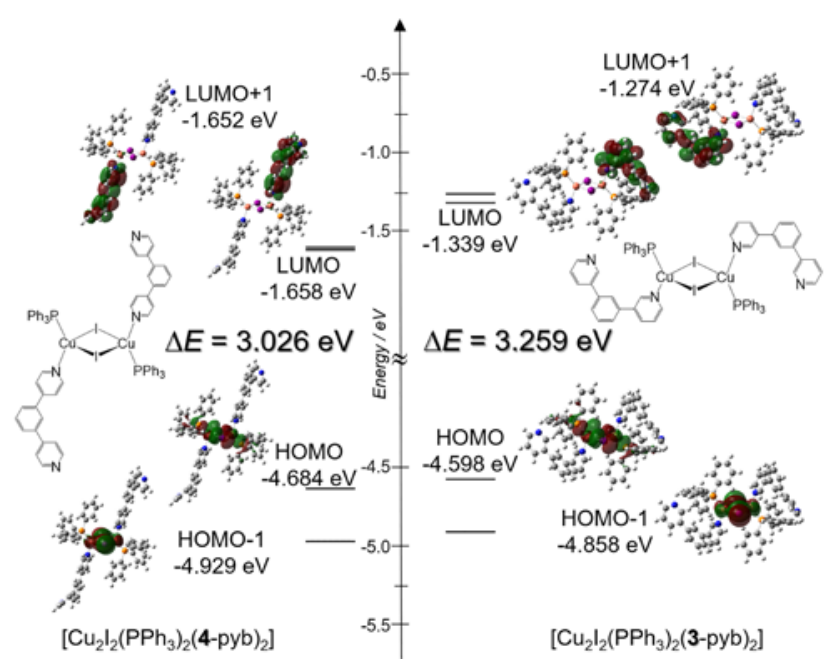

Figure 4. Schematic molecular orbital diagrams for the model dinuclear complexes, (left) $\left[\mathrm{Cu}_{2} \mathrm{I}_{2}\left(\mathrm{PPh}_{3}\right)_{2}(4-\mathrm{pyb})_{2}\right]$ and (right) $\left[\mathrm{Cu}_{2} \mathrm{l}_{2}\left(\mathrm{PPh}_{3}\right)_{2}(3-\mathrm{pyb})_{2}\right]$. The energy gap between HOMO and LUMO is also shown.

energy CT state compared to that of Cu-4-tpyb (as evidenced by the higher energy emission of Cu-3-tpyb by $\sim 45 \mathrm{~nm}$ at $298 \mathrm{~K}$. In other words, the rapid radiative decay process via TADF was the dominant pathway at $298 \mathrm{~K}$ because of the spin-allowed fluorescence character of the $S_{1}$ state, while it was strongly prohibited at a lower temperature of $78 \mathrm{~K}$. A slower radiative decay process was observed from the thermally accessible ${ }^{3} \pi-\pi$ state.

To further investigate the emission origins of the Cu-m-tpyb ( $\mathrm{m}$ $=3,4$ ) coordination polymers, DFT calculations were conducted for the simplified $\mathrm{Cu}(\mathrm{I})$ dinuclear complexes, $\left[\mathrm{Cu}_{2} \mathrm{I}_{2}\left(\mathrm{PPh}_{3}\right)_{2}(m-\right.$ pyb) $)_{2}$ ( $m=3,4, m$-pyb $=1,3-(m$-pyridyl)benzene $)$. Schematic molecular orbital diagrams of the ground states are shown in Figure 4. The structure optimizations were started from the X-ray structures by replacing the pyridyl group of the $m$-tpyb ligand coordinating to the adjacent $\mathrm{Cu}_{2} \mathrm{I}_{2}$ core by an $\mathrm{H}$ atom. In both simplified dinuclear complexes, the highest-occupied molecular orbital (HOMO) and HOMO-1 comprised the 3d orbitals of the two $\mathrm{Cu}(\mathrm{I})$ ions and the $5 \mathrm{p}$ orbitals of two iodide ions, while the lowest-unoccupied molecular orbital (LUMO) and LUMO+1 were delocalized on the $\pi^{\star}$ orbital of the $m$-pyb ligand. The energy difference between the HOMO and LUMO of $\left[\mathrm{Cu}_{2} \mathrm{I}_{2}\left(\mathrm{PPh}_{3}\right)_{2}(4-\right.$ $\mathrm{pyb})_{2}$ ] was larger (by $\sim 0.2 \mathrm{eV}$ ) compared to that of $\left[\mathrm{Cu}_{2} \mathrm{I}_{2}\left(\mathrm{PPh}_{3}\right)_{2}(3-\mathrm{pyb})_{2}\right]$. Since this difference estimated by DFT calculations was qualitatively matched with the difference of emission energy between Cu-4-tpyb and Cu-3-tpyb, the emission of Cu-m-tpyb could be originated from the metal-toligand charge-transfer state effectively mixed with the halide-toligand charge-transfer $((M+X) L C T)$ state. Accordingly, the higher-lying $\pi^{\star}$ orbital of 3-tpyb as compared to that of 4-tpyb was the origin of the shorter wavelength emission of Cu-3-tpyb than that of Cu-4-tpyb. Our DFT calculations also suggested that the ${ }^{3} \mathrm{CC}$ excited state with an effective $\mathrm{Cu}-\mathrm{Cu}$ interaction was hardly accessible; the LUMO with the bonding character between the two $\mathrm{Cu}(\mathrm{I})$ ion in the rhombic core was found at 
LUMO+27 and the energy difference from LUMO was above 2.6 $\mathrm{eV}$ (see Figures S3 and S4). This is consistent with the X-ray structures that showed longer $\mathrm{Cu} \ldots \mathrm{Cu}$ distances in the core (more than twice of the van der Waals radius of $\mathrm{Cu}$, as described in the section discussing crystal structures. We also checked the contribution of the ligand-centered $\pi-\pi^{\star}$ transition from the ground state MO diagrams. The highest-occupied $\pi$ orbital of the $m$-pyb ligand was found at HOMO-12 in $\left[\mathrm{Cu}_{2} \mathrm{I}_{2}\left(\mathrm{PPh}_{3}\right)_{2}(3-\mathrm{pyb})_{2}\right]$, but the corresponding orbital of $\left[\mathrm{Cu}_{2} \mathrm{I}_{2}\left(\mathrm{PPh}_{3}\right)_{2}(4-\mathrm{pyb})_{2}\right]$ was found at the more stable HOMO-19. The energy difference between these MOs and HOMOs was also smaller in $\left[\mathrm{Cu}_{2} \mathrm{I}_{2}\left(\mathrm{PPh}_{3}\right)_{2}(3-\mathrm{pyb})_{2}\right](1.78 \mathrm{eV})$ than that in $\left[\mathrm{Cu}_{2} \mathrm{I}_{2}\left(\mathrm{PPh}_{3}\right)_{2}(4-\mathrm{pyb})_{2}\right](2.10 \mathrm{eV})$. This result was experimentally supported by the UV-Vis absorption spectra of the $m$-tpyb ligands; the lowest absorption band of 3-tpyb was shifted to shorter wavelengths by about $15 \mathrm{~nm}$ compared to that of 4-tpyb in the $\mathrm{CHCl}_{3}$ solutions (Figure S5). Thus, the ${ }^{3} \pi-\pi^{\star}$ excited state of Cu-3-tpyb was likely more stable and accessible than that of Cu-4-tpyb, resulting in the observation of ${ }^{3} \pi-\pi^{\star}$ emission with a clear vibrational progression at $78 \mathrm{~K}$.

\section{Mechanochromic luminescence}

As discussed previously, solvated $\mathrm{CHCl}_{3}$ and water molecules were present in the porous channels of Cu-4-tpyb, suggesting the possibility of luminescence chromism based on the adsorption/desorption of these guest molecules. Thus, we investigated the changes in the emission spectra under various conditions. As shown in Figure 5(a), the emission spectrum of as-synthesized Cu-4-tpyb was hardly changed upon removal of the solvated $\mathrm{CHCl}_{3}$ and water molecules under vacuum (black and red curves in Figure 5(a)). Photographs of the crystalline samples of Cu-4-tpyb under bright field and UV light irradiation were also negligibly changed in this drying process (Figure 5(c) and 5(d)). Notably, the emission spectrum and photographs were remarkably changed by manually grinding the dried sample
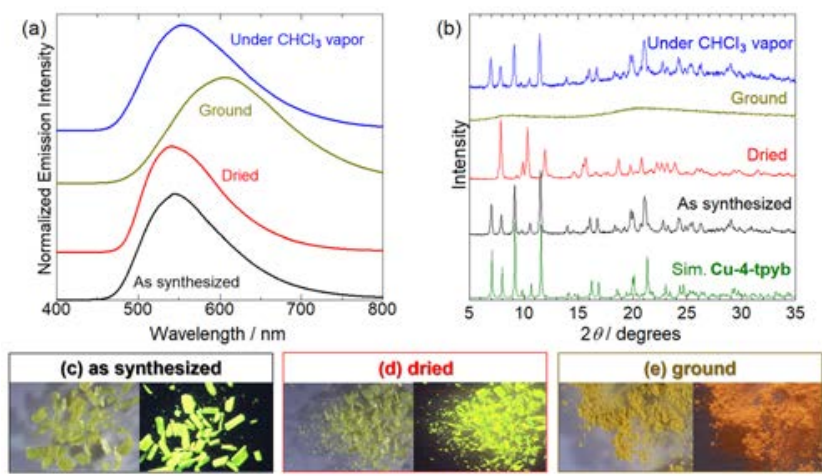

Figure 5. Changes in the (a) emission spectrum $\left(\lambda_{\mathrm{ex}}=350 \mathrm{~nm}\right)$ and (b) PXRD pattern of Cu-4-tpyb upon drying under vacuum (red), subsequent manual grinding in a mortar (brown), and exposure to $\mathrm{CHCl}_{3}$ vapor at room temperature (blue). Black lines in both panels show the spectrum and patterns of the as-synthesized Cu-4-tpyb. The green curve in (b) is the simulation pattern calculated based on the X-ray structure of Cu-4-tpyb. Photographs in (left) bright field and (right) under UV light of (c) as synthesized, (d) vacuumdried and (e) ground Cu-4-tpyb are shown. in a mortar; the emission maximum was observed at $605 \mathrm{~nm}$ and the color under bright field was changed from clear yellow to brown after grinding (brown curve in Figure 5(a) and 5(e)). Further, the original emission spectrum with the maximum at $545 \mathrm{~nm}$ was recovered by exposing the ground sample to $\mathrm{CHCl}_{3}$ vapor in air (blue curve in Figure 5(a)). These results indicate that Cu-4-tpyb exhibits mechanochromic luminescence upon manual grinding and exposure to $\mathrm{CHCl}_{3}$ vapor. Similar spectral changes were observed in the excitation and UV-Vis diffuse reflectance spectra (see Figure S6), suggesting that the mechanochromic behavior likely originated from the structural transformation in the ground state and not structural relaxation in the excited state.

To elucidate the mechanism of the mechanochromic luminescence of Cu-4-tpyb, PXRD patterns of these four different samples were measured. As shown in Figure 5(b), assynthesized Cu-4-tpyb exhibited an almost identical pattern to the simulation calculated from the X-ray structure, while the diffraction pattern of the dried sample was completely different to that of the as-synthesized sample. Considering the thermogravimetric analysis (TGA) results showing that all solvated $\mathrm{CHCl}_{3}$ and water molecules were removed under vacuum (see Figure S7), the change in the PXRD pattern indicates that the porous structure of Cu-4-tpyb could not be retained without the solvated guest molecules in the pores. On the other hand, the almost identical emission spectra of the assynthesized and dried samples suggest that the collapse of the porous structure hardly affected the $(\mathrm{M}+\mathrm{X}) \mathrm{LCT}$ transition energy of Cu-4-tpyb. In contrast, no sharp peak was observed in the PXRD pattern of the ground sample, indicating that grinding induced amorphization. The remarkable changes in color and emission upon grinding suggest that amorphization influences the structure around the $\left\{\mathrm{Cu}_{2} \mathrm{I}_{2}\right\}$ core. After exposing the ground sample to $\mathrm{CHCl}_{3}$ vapors in air, an almost identical PXRD pattern to that of the as-synthesized sample was observed. These changes in the PXRD experiments clearly revealed that the reversible crystal-to-amorphous transformation was the origin of mechanochromic luminescence of Cu-4-tpyb.

Since the remarkable color and luminescence changes and the mechanochromic behavior of Cu-4-tpyb suggested a change in the origin of luminescence, the emission lifetime and quantum yield of the ground sample were determined at 298 and $78 \mathrm{~K}$. The observed emission decay curves of ground $\mathrm{Cu}-4$-tpyb at 298 and $78 \mathrm{~K}$ are shown in Figures 6(a) and 6(b), respectively, and compared with that of the as-synthesized sample (the same data shown in Figure 3(c)). The results and estimated $k_{\mathrm{r}}$ and non-radiative decay constant $\left(k_{\mathrm{nr}}\right)$ are listed in Table 1 . The emission quantum yield decreased to one third of the assynthesized sample at both temperatures upon manual grinding. Although the emission lifetime of the ground sample was also estimated to decrease to one-third, the observed emission decay curve could be fitted by at least triple exponentials $\left(\tau_{1}, \tau_{2}\right.$, and $\tau_{3}$ ) at both 298 and $78 \mathrm{~K}$. Considering that a single exponential decay was observed in the emission decay of the as-synthesized Cu-4-tpyb, different emissive state(s) may be generated in the ground sample. Further investigation of the origin of emission for the ground sample was conducted by 
variable-temperature emission lifetime experiments (Figures 6(c) and $6(d))$. In this low temperature range, three different emission components were commonly observed, and the main contribution was that of the middle lifetime component $\tau_{2}$; the component fraction of $\tau_{2}$ was constantly over $50 \%$ in this temperature range (see Figure 6(c)). The temperature dependence of the longest-lived emission component $\left(\tau_{3}\right)$ qualitatively in agreement with that of the as-synthesized sample and successfully fitted by equation (1) (blue dotted curve in Figure $6(\mathrm{c})$ ), suggesting the existence of the same TADF emission species with the ${ }^{3}(M+X) L C T$ character. However, the component fraction was less than $25 \%$ at all measured temperatures. In contrast, the two shorter-lived emission species ( $\tau_{1}$ and $\tau_{2}$ ) exhibited completely different temperature dependence to that of the $\tau_{3}$ component; the smaller temperature dependences of the emission lifetimes ranging from 0.44 to $23 \mu \mathrm{s}$ clearly indicated the contribution of the other emission species. It should be noted that a comparable emission lifetime was observed for several cubane-type $\mathrm{Cu}(\mathrm{I})$ cluster complexes (e.g., $\left.\left[\mathrm{Cu}_{4} \mathrm{l}_{4}\left(\mathrm{PPh}_{3}\right)_{4}\right]\right)$, which showed that phosphorescence originated from the ${ }^{3} \mathrm{CC}$ excited state as mentioned above. ${ }^{18,20}$ Although the structure of ground $\mathrm{Cu}-4$ tpyb was still unclear owing to its amorphous nature, it was possible for the ground Cu-4-tpyb to form the cubane-type $\left\{\mathrm{Cu}_{4} \mathrm{I}_{4}\right\}$ cluster, which is the typical structure for ${ }^{3} \mathrm{CC}$ emissive complexes, because the moderate void fraction in the unit cell $(\sim 20 \%)$ likely allowed the drastic structural transformation from the rhombic-type $\left\{\mathrm{Cu}_{2} \mathrm{I}_{2}\right\}$ core to the cubane-type $\left\{\left.\mathrm{Cu}_{4}\right|_{4}\right\}$ core. Thus, the temperature dependence of the emission lifetime of ground Cu-4-tpyb suggests that the mechanochromic luminescence of Cu-4-tpyb involves a unique switching of the emission origin between TADF from the $(M+X) L C T$ excited state and phosphorescence derived from the ${ }^{3} \mathrm{CC}$ excited state.

We also investigated the mechanochromic behavior of $\mathrm{Cu}-3-$ tpyb because this coordination polymer has similar porous channels and 1-D coordination chains as that of Cu-4-tpyb.
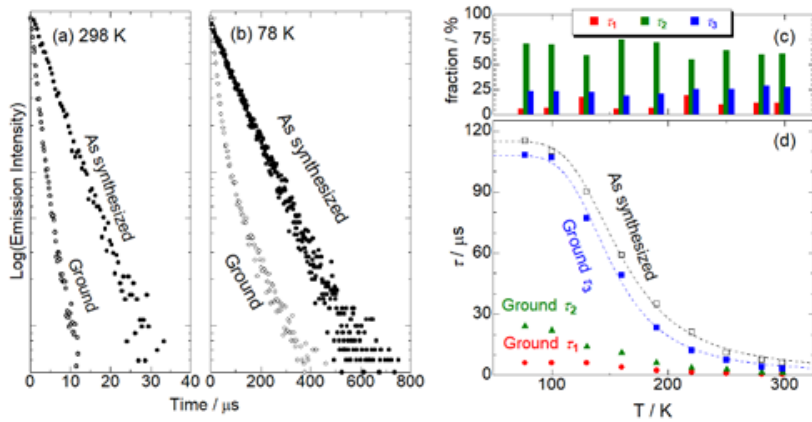

Figure 6. Emission decays of the as-synthesized (closed circles) and ground samples (open circles) of Cu-4-tpyb at (a) $298 \mathrm{~K}$ and (b) $78 \mathrm{~K}$ in the solid state $\left(\lambda_{\mathrm{ex}}=337 \mathrm{~nm}\right)$. Temperature dependence of $(\mathrm{c})$ the fraction and $(\mathrm{d})$ lifetime of each emission component (red, green, and blue symbols represent the emission components with short $\left(\tau_{1}\right)$, middle $\left(\tau_{2}\right)$, and long $\left(\tau_{3}\right)$ lifetimes) observed for the ground sample of Cu-4-tpyb. Data of the as-synthesized $\mathrm{Cu}$ 4-tpyb is also shown in (d)
Figures 7(a) and 7(b) display the changes in the emission spectrum and PXRD pattern of Cu-3-tpyb under various conditions. The as-synthesized sample exhibited light blue emission (Figure 7(c)) with the maximum at $498 \mathrm{~nm}$ and the PXRD pattern was identical to the one simulated based on the $\mathrm{X}$-ray structure. Although the emission spectrum of Cu-4-tpyb hardly showed any change upon drying under vacuum as discussed above, the luminescence color of Cu-3-tpyb turned bluish-green as shown in Figure 7(d) upon vacuum-drying and the emission maximum was red-shifted by about $17 \mathrm{~nm}$ Furthermore, the intensity of the strongest (010) diffraction peak of the as-synthesized sample observed at $6.6^{\circ}$ decreased significantly and most peaks shifted to higher angles. Additional changes in the emission spectrum and PXRD pattern were observed upon drying for the second time by heating to $120^{\circ} \mathrm{C}$; the luminescence color was changed to light green (Figure $7(\mathrm{e})$ ) and the wavelength of emission maximum was red-shifted to $545 \mathrm{~nm}$. The strongest diffraction peak in the PXRD pattern was also shifted to a higher angle $\left(7.6^{\circ}\right)$. These results suggest that the solvated THF molecules in Cu-3-tpyb were removed in two steps. In fact, TG analyses of these two dried samples under vacuum at room temperature and at $120^{\circ} \mathrm{C}$ in air clearly indicate that one of the two solvated THF molecules could be removed by drying under vacuum whereas all solvated THF and water molecules were removed by heated drying (see Figure S8). This result is reasonable because there are two different porous channels in the crystal structure of Cu-3-tpyb; one of the two channels was occupied by only THF and the other was filled by THF and water molecules (Figure 2(b)). Thus, these changes observed in the emission spectrum may be attributed to the removal of solvated molecules from the porous structure of $\mathrm{Cu}$ 3-tpyb, which involves significant changes in the crystal structure. Interestingly, the emission color was changed to greenish-yellow upon manual grinding of all the three states (Figure 7(f)). Same as Cu-4-tpyb, the PXRD pattern of ground Cu-3-tpyb exhibited a featureless broad pattern, indicating
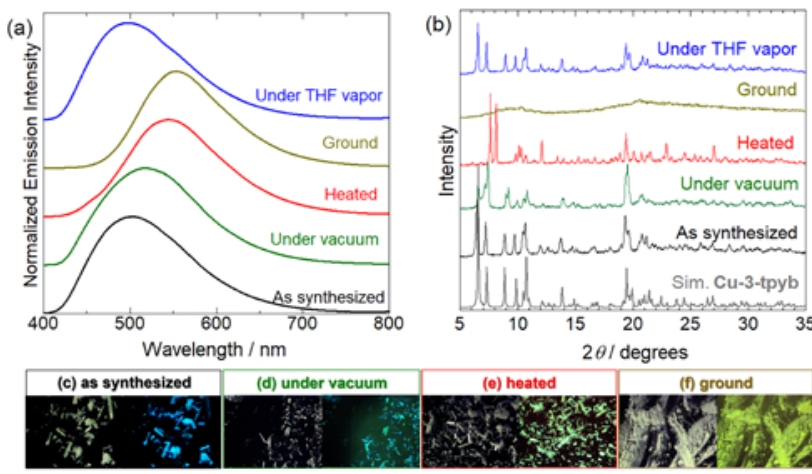

Figure 7. Changes in the (a) emission spectrum $\left(\lambda_{\mathrm{ex}}=350 \mathrm{~nm}\right)$ and (b) PXRD pattern of Cu-3-tpyb by (green) drying under vacuum, and subsequent (red) heating, (orange) manual grinding, and (blue) exposure to THF vapor at room temperature. Black curves show the spectrum and pattern of the as synthesized sample. Gray curve at the bottom in (b) shows the simulation pattern calculated from the crystal structure of Cu-3-tpyb. Photographs in (left) bright field and (right) under UV light of the (c) as-synthesized, (d) vacuumdried, (e) heat-dried, and (d) ground Cu-3-tpyb are shown. 
amorphization as a result of manual grinding. The original light blue emission and almost identical PXRD pattern to the simulation based on the X-ray structure of Cu-3-tpyb were recovered by exposing these dried and/or ground samples to THF vapor in air. These changes observed in the emission spectrum and PXRD pattern clearly indicate that Cu-3-tpyb exhibits reversible luminescent vapochromism and mechanochromism. To elucidate the emission origin of the ground Cu-3-tpyb, the emission decay and quantum yield were evaluated. Obtained results and estimated $k_{\mathrm{r}}$ and $k_{\mathrm{nr}}$ values are summarized in Table 1 . Interestingly, the emission quantum yield of ground Cu-3-tpyb was comparable $(\Phi=0.30$ at $298 \mathrm{~K}$ and 0.67 at $78 \mathrm{~K}$ ) to that of the as-synthesized sample whereas the emission lifetime of the ground sample was remarkably shorter by about half of the as-synthesized sample at both 298 and $78 \mathrm{~K}$ (Figure S9). Estimated $k_{\mathrm{r}}$ value of the ground state was remarkably higher by about two and three times than that of the as-synthesized sample, indicating the contribution of the different emissive states. As discussed before, the emission of the as-synthesized Cu-3-tpyb could be attributed to TADF that derived from the $(M+X) L C T$ emissive state at $\sim 298 \mathrm{~K}$ in addition to the phosphorescence from the ligand-centered $\pi-\pi^{\star}$ excited state at $78 \mathrm{~K}$. On the other hand, sharp peaks characteristic of ${ }^{3} \pi-\pi^{\star}$ emission were hardly observed for the ground sample in the time-resolved emission spectrum at $78 \mathrm{~K}$ (see Figure S10). Thus, the $(M+X) L C T$ emissive state was stabilized by grindinginduced amorphization than the ${ }^{3} \pi-\pi^{\star}$ state. Since the triple exponential decay was observed even for the as-synthesized crystal of Cu-3-tpyb, the assignment for each emission component observed for the ground sample is difficult. However, the emission lifetime of the shortest-lived component was in the same time range as that of the emission assigned to the ${ }^{3} \mathrm{CC}$ transition of ground $\mathrm{Cu}-4$-tpyb, suggesting that the ${ }^{3} \mathrm{CC}$ excited state contributed to the emission properties of ground $\mathrm{Cu}$-3-tpyb as well as Cu-4-tpyb.

\section{Plausible mechanism of mechanochromic luminescence}

As mentioned previously, both Cu-m-tpyb $(m=3,4)$ exhibited a unique mechanochromic luminescence involving switching between TADF and phosphorescence. In this section, we discuss a plausible mechanism of this switching behavior. Scheme 2 shows the schematic energy diagrams of both the assynthesized and ground samples of Cu-4-tpyb. As indicated by $\mathrm{X}$-ray structures and DFT calculations for the simplified dinuclear complexes $\left[\mathrm{Cu}_{2} \mathrm{I}_{2}\left(\mathrm{PPh}_{3}\right)_{2}(m \text {-pyb })_{2}\right]$, the metallophilic interactions between the two $\mathrm{Cu}(\mathrm{I})$ ions in the rhombic core were negligible for both Cu-m-tpyb. Thus, ${ }^{3} \mathrm{CC}$ emission was hardly observed for the as-synthesized samples. DFT calculations also suggested that the HOMO and LUMO were localized on the rhombic $\left\{\mathrm{Cu}_{2} \mathrm{I}_{2}\right\}$ core and the pyb ligand (see Figure 4). This specially separated electronic structure should contribute to the small energy gap between the singlet and triplet $(M+X) L C T$ excited state. Consequently, TADF originating from the $(M+X) L C T$ excited state was observed for both Cu-m-tpyb $(m=3,4)$ (Scheme 2(a)). This is consistent with the small energy gap $\left(\Delta E=650 \mathrm{~cm}^{-1}\right)$ estimated by the temperature
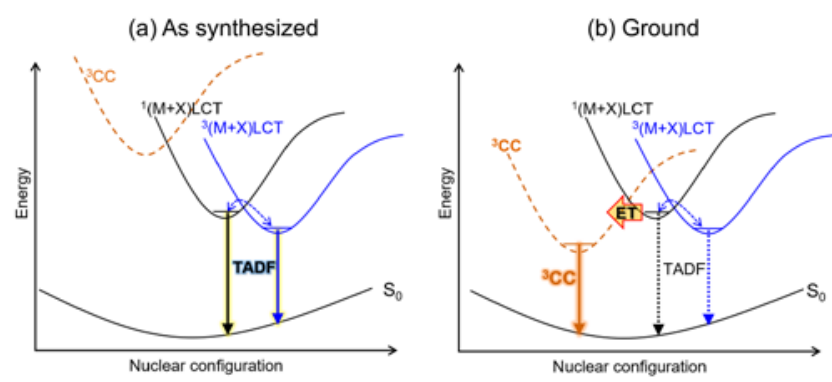

Scheme 2. Schematic energy diagrams of the (a) as-synthesized and (b) ground samples of Cu-4-tpyb.

dependence of emission lifetimes (see Figure 3(e)). On the other hand, the structure of the ground samples of Cu-m-tpyb is still unclear because of their amorphous nature, although an almost identical IR spectrum to that of the dried samples was observed (Figure S11), which suggested that 1-D coordination chain structures would be retained after grinding-induced amorphization, even though the range of the structural ordering should be shorter than that in the as-synthesized sample. Considering that the weak lower-energy absorption and excitation bands appeared on grinding (Figure S6), it is reasonable to expect that some defects and/or impurity sites would be formed. One plausible origin of such an impurity site might be the cubane-type $\left\{\left.\mathrm{Cu}_{4}\right|_{4}\right\}$ cores that could be formed upon breaking of 1-D coordination chains and the following dimerization of the coordinatively unsaturated $\left\{\mathrm{Cu}_{2} \mathrm{I}_{2}\right\}$ dimers at the terminals. Plausibly, the lower-energy ${ }^{3} \mathrm{CC}$ emission was observed as the dominant component for the ground samples because of a Dexter-type energy transfer from the higher-energy $(\mathrm{M}+\mathrm{X}) \mathrm{LCT}$ excited states through the 1-D coordination chains (i.e., energy migration). Such emission via energy migration through 1-D coordination chains has been previously reported by Tsuge et al.; the $\mathrm{Cu}(\mathrm{I})-\mathrm{Ag}(\mathrm{I})$ mixed metal luminescent coordination polymer, $\left[\mathrm{Ag}_{2-x} \mathrm{Cu}_{x} \mathrm{l}_{2}\left(\mathrm{PPh}_{3}\right)_{2}(\mathrm{bpy})\right]_{n}$, exhibited emissions that originated from the $\mathrm{Cu}(\mathrm{I})$ site as the dominant species even in the extremely low $\mathrm{Cu}(\mathrm{I})$ dopant concentration $(x$ $=0.005) \cdot{ }^{49}$ Thus, in the emission of ground samples of Cu-mtpyb $(m=3,4)$, the $(M+X) L C T$ excitons generated in the 1-D coordination chains could migrate and get captured by the impurity site with the lower-energy ${ }^{3} \mathrm{CC}$ emissive state. In fact, the mechanochromic switching behavior of Cu-4-tpyb strongly depended on the degree of manual grinding; the lightly ground sample exhibited a long emission lifetime comparable to that of the as-synthesized sample (Figure S12), implying that the breaking of 1-D coordination chains by manual grinding is an important step to generate the lower-energy ${ }^{3} \mathrm{CC}$ emissive state. In the case of Cu-3-tpyb, the mechanochromic behavior was more complicated than that of Cu-4-tpyb because of the contribution of the ligand-centered ${ }^{3} \pi-\pi$ emissive state. However, the shorter $\mathrm{Cu}(\mathrm{I}) \cdots \mathrm{Cu}(\mathrm{I})$ distance in the rhombic $\left\{\mathrm{Cu}_{2} \mathrm{I}_{2}\right\}$ core and the larger void fraction of Cu-3-tpyb compared to those in Cu-4tpyb (Table S2) implied that the cubane-type $\left\{\mathrm{Cu}_{4} \mathrm{I}_{4}\right\}$ structure was easily formed as the impurity site during the grindinginduced amorphization process. Therefore, we believe that the 
emission origin of Cu-3-tpyb was switched between TADF and phosphorescence in the mechanochromic luminescence behavior.

\section{Conclusions}

Two new luminescent $\mathrm{Cu}(\mathrm{I})$ coordination polymers $\mathrm{Cu}-\mathrm{m}$-tpyb, formulated as $\left[\mathrm{Cu}_{2} \mathrm{l}_{2}\left(\mathrm{PPh}_{3}\right)_{2}(m \text {-tpyb) }]_{n}\right.$, were synthesized. X-ray diffraction study revealed that 1-D coordination chains comprising rhombic $\left\{\mathrm{Cu}_{2} \mathrm{I}_{2}\left(\mathrm{PPh}_{3}\right)_{2}\right\}$ cores and the bridging $m$-tpyb ligands were commonly formed in both complexes and solvated guest molecules existed in between the chains. Both Cu-m-tpyb $(m=3,4)$ exhibited interesting TADF that was derived from the singlet and triplet $(\mathrm{M}+\mathrm{X}) \mathrm{LCT}$ excited states as suggested by the temperature dependence of the emission lifetime and DFT calculations, which were based on the simplified dinuclear $\mathrm{Cu}(\mathrm{I})$ complexes, $\left[\mathrm{Cu}_{2} \mathrm{I}_{2}\left(\mathrm{PPh}_{3}\right)_{2}(m-\mathrm{pyb})_{2}\right]$. Although the luminescence color of Cu-4-tpyb was hardly changed by the removal of the solvated guest molecules, remarkable mechanochromic luminescence was observed by manual grinding and exposure to $\mathrm{CHCl}_{3}$ vapor. In contrast, interesting vapochromic luminescence was observed in addition to the similar mechanochromic luminescence of Cu-4-tpyb for Cu-3-tpyb in response to the adsorption/desorption of the solvated THF molecules. The unique mechanochromic switching between TADF derived from the $(M+X) L C T$ excited states and phosphorescence, which originated from the ${ }^{3} \mathrm{CC}$ state, was suggested by the temperature dependence of the emission lifetime of the ground samples. A plausible mechanism is the energy transfer from the $(M+X) L C T$ excited state to the lowerenergy ${ }^{3} \mathrm{CC}$ emissive state of the impurity sites that were generated by the grinding-induced amorphization of Cu-m-tpyb. Further studies of the switching of emission origin as a result of various external stimuli is now in progress.

\section{Experimental Section}

\section{Synthesis}

Organic bridging ligands, 4-tpyb and 3-tpyb, were prepared according to the literature procedure. ${ }^{46,47}$ Copper iodide was purchased from Wako Pure Chemical Industries, Ltd. Triphenylphosphine $\left(\mathrm{PPh}_{3}\right)$ and solvents used in this work were purchased from Kanto Chemical Co. Inc. All reagents were used as received.

\section{Synthesis of $\left[\mathrm{Cu}_{2} \mathrm{I}_{2}(4-\mathrm{tpyb})_{2}\left(\mathrm{PPh}_{3}\right)_{2}\right]_{n}$ (Cu-4-tpyb)}

Cul (19.1 mg, $100 \mu \mathrm{mol})$ was added to a solution of $\mathrm{PPh}_{3}(55.2 \mathrm{mg}, 210$ $\mu \mathrm{mol})$ in a mixture of $\mathrm{MeOH}(1 \mathrm{~mL})$ and $\mathrm{CHCl}_{3}(2 \mathrm{~mL})$. After stirring for 15 $\mathrm{min}$ at room temperature, the bridging ligand, 4-tpyb (15.2 mg, 48.2 $\mu \mathrm{mol})$ was added and the reaction mixture was stirred for another $5 \mathrm{~min}$ at room temperature. Subsequently, the mixture was filtered to remove the unreacted insoluble materials. After standing the filtrate for several days at $30{ }^{\circ} \mathrm{C}$, yellow crystals were collected by filtration and washed using a small amount of $\mathrm{CHCl}_{3}$. Yield: $30.7 \%(22.0 \mathrm{mg}, 14.9 \mu \mathrm{mol})$. Anal. Calcd. for $\mathrm{C}_{57} \mathrm{H}_{45} \mathrm{Cu}_{2} \mathrm{l}_{2} \mathrm{~N}_{3} \mathrm{P}_{2}$ (\%): C, 56.35; $\mathrm{H}, 3.73 ; \mathrm{N}, 3.46$. Found (\%): C, 56.12; H, 3.60; N, 3.38. IR ( $\left.\mathrm{KBr} \mathrm{cm}^{-1}\right): 3070$ m, $3048 \mathrm{~m}, 3030 \mathrm{w}, 3000 \mathrm{w}$,
1600 vs, 1552 m, 1499 m, 1480 s, 1435 vs, 1406 s, 1322 w, 1220 w, 1184 w, 1155 w, 1094 s, 1069 m, 1028 w, 1011 w, 994 w, 840 m, 815 vs, 743 vs, 694 vs, 627 s, 618 s, 523 s, 510 s, 486 m.

\section{Synthesis of $\left[\mathrm{Cu}_{2} \mathrm{l}_{2}(3-\mathrm{tpyb})_{2}\left(\mathrm{PPh}_{3}\right)_{2}\right]_{n}$ (Cu-3-tpyb)}

Cul $(19.1 \mathrm{mg}, 100 \mu \mathrm{mol})$ was added to the THF solution of $\mathrm{PPh}_{3}(55.2$ $\mathrm{mg}, 210 \mu \mathrm{mol}$ in $5 \mathrm{~mL}$ ) and the mixture was stirred for $15 \mathrm{~min}$ at $40^{\circ} \mathrm{C}$. The bridging ligand, 3-tpyb $(15.2 \mathrm{mg}, 48.3 \mu \mathrm{mol})$, was added to the reaction mixture of Cul and $\mathrm{PPh}_{3}$. After stirring for $5 \mathrm{~min}$ at room temperature, the insoluble impurities were removed by filtration. After standing the filtrate for several days at $30{ }^{\circ} \mathrm{C}$, the pale-yellow crystals were collected by filtration and washed using a small amount of THF. Yield: $29.5 \%$ (19.0 mg, $15.7 \mu \mathrm{mol})$. Anal. Calcd. for $\mathrm{C}_{61} \mathrm{H}_{53} \mathrm{Cu}_{2} \mathrm{l}_{2} \mathrm{~N}_{3} \mathrm{OP}_{2}$ (\%): C, 56.93; H, 4.15; N, 3.27. Found (\%): C, 56.70; H, 4.30; N, 3.12. IR $\left(\mathrm{KBr} \mathrm{cm}{ }^{-1}\right): 3052 \mathrm{~m}, 2974 \mathrm{~m}, 2857 \mathrm{~m}, 1711 \mathrm{w}, 1602 \mathrm{~m}, 1586 \mathrm{w}, 1572 \mathrm{~m}$, 1482 vs, 1436 vs, 1418 m, 1389 m, 1325 m, 1191 m, 1160 w, 1130 w, 1110 w, 1095 s, 1066 m, 1047 w, 1027 m, 1011 w, 997 w, 881 w, 800 m 747 vs, 695 vs, 512 s, 500 s, 495 s.

\section{Measurements}

Elemental analysis of each complex was conducted at the Analysis Center of Hokkaido University, Japan. IR spectra were recorded on a JASCO FT/IR-4100 spectrophotometer as $\mathrm{KBr}$ pellets. Emission and excitation spectra were measured by using JASCO FP-8600 spectrofluorometer. UV-Vis diffuse-reflectance and absorption spectra were recorded on a Shimadzu UV-2400PC spectrophotometer equipped with an integrating sphere apparatus. UV-vis diffuse-reflectance spectra were converted to absorption spectra using the Kubelka-Munk function $F\left(R_{\infty}\right)$. Emission quantum yields were measured on a Hamamatsu C9920-02 absolute photoluminescence quantum yield measurement system equipped with an integrating sphere apparatus and a $150 \mathrm{~W} \mathrm{CW}$ xenon light source. Emission lifetimes and time-resolved emission spectra were assessed using the Hamamatsu Photonics C4334 system, equipped with a streak camera as a photodetector and a nitrogen laser as an excitation light source $\left(\lambda_{\mathrm{ex}}=337 \mathrm{~nm}\right)$. A liquid-nitrogen cryostat (Oxford Optistat-DN and ITC- 503 temperature controllers) was used to control the sample temperature. PXRD was conducted using a Bruker D8 Advance diffractometer equipped with a graphite monochromator using $\mathrm{Cu} \mathrm{Ka}$ radiation and a one-dimensional LinxEye detector. Thermogravimetric and differential thermal analysis (TG-DTA) were conducted using a Rigaku ThermoEvo TG8120 analyzer. Single-crystal $\mathrm{X}$-ray diffraction measurements at $150 \mathrm{~K}$ were performed using a Rigaku Mercury CCD diffractometer with graphite monochromated Mo Ka radiation $(\lambda=0.71075 \AA)$ and a rotating anode generator. Low temperature single-crystal $\mathrm{X}$-ray diffraction experiment at $97 \mathrm{~K}$ was conducted by using Rigaku XtaLAB Synergy diffractometer with $\mathrm{Cu}$ Ka radiation (PhotonJet $(\mathrm{Cu})$ ). Each crystal was mounted on a loop using paraffin oil. Diffraction data at $150 \mathrm{~K}$ were corrected and processed using Crystalclear. ${ }^{50}$ The data at $97 \mathrm{~K}$ were corrected and processed using CrysAlisPRO software. ${ }^{51}$ The structures at 150 and $97 \mathrm{~K}$ were determined by direct methods using SHELXS2013 and SHELXT, respectively. ${ }^{52}$ All structure refinements were conducted by the full-matrix least-squares method using SHELXL. ${ }^{50}$ All nonhydrogen atoms were refined anisotropically, while hydrogen atoms were refined using the riding model. CrystalStructure ${ }^{53}$ and Olex $2^{54}$ were used for all calculations for the data at 150 and $97 \mathrm{~K}$, respectively. Crystallographic data for Cu-4-tpyb and Cu-3-tpyb are summarized in Table S1. Full crystallographic data have been deposited with the Cambridge Crystallographic Data Centre (CCDC 1843260, 1843261, 1852147)

Theoretical calculations 
All density-functional-theory (DFT) calculations were performed using the Gaussian 09W program. ${ }^{55}$ Geometry optimization of $\left[\mathrm{Cu}_{2} \mathrm{I}_{2}\left(\mathrm{PPh}_{3}\right)_{2}(m\right.$ pyb) ${ }_{2}$ ] was achieved using the Becke3LYP functional ${ }^{56,57}$ as implemented in the Gaussian09 program. Cartesian coordinates of the optimized structures are given in Table S3. The SDD basis sets ${ }^{58,59}$ and the associated effective core potentials were used for $\mathrm{Cu}$ and I, and the 6$31 \mathrm{G}(\mathrm{d})$ basis sets ${ }^{60-61}$ were used for the remaining atoms.

\section{Acknowledgements}

This study was supported by the Shimadzu Science Foundation, the Shorai Science and Technology Foundation, the Murata Science Foundation, Grant-in-Aid for Scientific Research (C)(26410063), Artificial Photosynthesis (Area No. 2406, No.15H00858), and Soft Crystals (Area No. 2903, No. JP17H06367) from MEXT, Japan.

\section{Keywords: Mechanochromism • Delayed fluorescence •} Phosphorescence $\bullet$ Luminescence $\bullet \mathrm{Cu}(\mathrm{I})$ complex

[1] C. Kutal, Coord. Chem. Rev. 1990, 99, 213-252.

[2] A. Barbieri, G. Accorsi, N. Armaroli, Chem. Commun. 2008, 2185-2193.

[3] M. Wallesch, D. Volz, D. M. Zink, U. Schepers, M. Nieger, T. Baumann, S. Bräse, Chem. Eur. J. 2014, 20, 6578-6590.

[4] V. W.-W. Yam, V. K.-M. Au, S. Y.-L. Leung, Chem. Rev. 2015, 115, 7589-7728.

[5] E. Cariati, E. Lucenti, C. Botta, U. Giovanella, D. Marinotto, S. Righetto, Coord. Chem. Rev. 2015, 306, 566-614.

[6] K. Tsuge, Y. Chishina, H. Hashiguchi, Y. Sasaki, M. Kato, S. Ishizaka, N. Kitamura, Coord. Chem. Rev. 2016, 306, 636-651.

[7] A. Kobayashi, M. Kato, Chem. Lett. 2017, 46, 154-162.

[8] R. Czerwieniec, J. Yu, H. Yersin, Inorg. Chem. 2011, 50, 8293-8301.

[9] H. Ohara, A. Kobayashi, M. Kato, Dalton Trans. 2014, 43, 1731717323.

[10] G. Blasse, D. R. McMillin, Chem. Phys. Lett. 1980, 70, 1-3.

[11] C. E. A. Palmer, D. R. McMillin, Inorg. Chem. 1987, 23, 3837-3840.

[12] A. Tsuboyama, K. Kuge, M. Furugori, S. Okada, M. Hoshino, K. Ueno, Inorg. Chem. 2007, 46, 1992-2001.

[13] M. J. Leitl, F.-R. Küchle, H. A. Mayer, H. Wesemann, H. Yersin, J. Phys. Chem. A 2013, 117, 11823-11836.

[14] M. J. Leitl, V. A. Krylova, P. I. Djurovich, M. E. Thompson, H. Yersin, J. Am. Chem. Soc. 2014, 136, 16032-16038.

[15] T. Hofbeck, U. Monkowius, H. Yersin, J. Am. Chem. Soc. 2015, 137, 399-404.

[16] F. Zhang, Y. Guan, X. Chen, S. Wang, D. Liang, Y. Feng, S. Chen, S. Li, Z. Li, F. Zhang, C. Lu, G. Cao, B. Zhai, Inorg. Chem. 2017, 56, 3742-3753.

[17] K. R. Kyle, J. A. DiBenedetto, P. C. Ford, J. Chem. Soc., Chem. Commun. 1989, 714-715.

[18] K. R. Kyle, C. K. Ryu, J. A. DiBenedetto, P. C. Ford, J. Am. Chem. Soc 1991, 113, 2954-2965.

[19] E. Cariati, J. Bourassa, P. C. Ford, Chem. Commun. 1998, 1623-1624

[20] H. Kitagawa, Y. Ozawa, K. Toriumi, Chem. Commun. 2010, 46, 63026304.

[21] S. Perruchas, X. F. Le Goff, S. Maron, I. Maurin, F. Guillen, A. Garcia T. Gacoin, J.-P. Boilot, J. Am. Chem. Soc. 2010, 132, 10967-10969.

[22] S. Perruchas, C. Tard, X. F. Le Goff, A. Fargues, A. Garcia, S. Kahlal J.-Y. Saillard, T. Gacoin, J.-P. Boilot, Inorg. Chem. 2011, 50, 10682 10692.

[23] A. Kobayashi, K. Komatsu, H. Ohara, W. Kamada, Y. Chishina, K. Tsuge, H.-C. Chang, M. Kato, Inorg. Chem. 2013, 52, 13188-13198.
[24] S.-Z. Zhan, M. Li, S. W. Ng, D. Li, Chem. Eur. J. 2013, 19, 1021710225.

[25] X.-C. Shan, F.-L. Jiang, L. Chen, M.-Y. Wu, J. Pan, X.-Y. Wan, M.-C Hong, J. Mat. Chem. C 2013, 1, 4339-4349.

[26] T. Hayashi, A. Kobayashi, H. Ohara, M. Yoshida, T. Mastumoto, H.-C Chang, M. Kato, Inorg. Chem. 2015, 54, 8905-8913.

[27] F. Farinella, L. Maini, P. P. Mazzeo, V. Fattori, F. Monti, D. Braga, Dalton Trans. 2016, 45, 17939-17947.

[28] H. Park, E. Kwon, H. Chiang, H. Im, K. Y. Lee, J. Kim, T. H. Kim, Inorg. Chem. 2017, 56, 8287-8294.

[29] D. V. Scaltrito, D. W. Thompson, J. A. O'Callaghan, G. J. Meyer, Coord. Chem. Rev. 2000, 208, 243-266.

[30] N. Armaroli, Chem. Soc. Rev. 2001, 30, 112-124.

[31] D. Felder, J.-F. Nierengarten, F. Barigelletti, B. Ventura, N. Armaroli, J. Am. Chem. Soc. 2001, 123, 6291-6299.

[32] D. G. Cuttell, S.-M. Kuang, P. E. Fanwick, D. R. McMillin, R. A. Walton J. Am. Chem. Soc. 2002, 124, 6-7.

[33] Z. A. Siddique, Y. Yamamoto, T. Ohno, K. Nozaki, Inorg. Chem. 2003 42, 6366-6378.

[34] T. McCormick, W.-L. Jia, S. Wang, Inorg. Chem. 2006, 45, 147-155.

[35] C. E. McCusker, F. N. Castellano, Inorg. Chem. 2013, 52, 8114-8120.

[36] A. Kobayashi, R. Arata, T. Ogawa, M. Yoshida, M. Kato, Inorg. Chem. 2017, 56, 4280-4288.

[37] D. Kakizoe, M. Nishikawa, Y. Fujii, T. Tsubomura, Dalton Trans. 2017, 46, 14804-14811

[38] M. Mohankumar, M. Holler, E. Meichsner, J.-F. Nierengarten, F. Niess, J.-P. Sauvage, B. Delavaux-Nicot, E. Leoni, F. Monti, J. M. Malicka, M. Cocchi, E. Bandini, N. Armaroli, J. Am. Chem. Soc. 2018, 140, 23362347

[39] H. Araki, K. Tsuge, Y. Sasaki, S. Ishizaka, N. Kitamura, Inorg. Chem 2005, 44, 9667-9675.

[40] H. Ohara, A. Kobayashi, M. Kato, C. R. Chemie, 2015, 18, 766-775.

[41] Y. Okano, H. Ohara, A. Kobayashi, M. Yoshida, M. Kato, Inorg. Chem 2016, 55, 5227-5236.

[42] P. C. Ford, E. Cariati, Chem. Rev. 1999, 99, 3625-3647.

[43] F. Sabin, C. K. Ryu, P. C. Ford, A. Vogler, Inorg. Chem. 1992, 31 1941-1945.

[44] B. K. Maiti, K. Pal, S. Sarkar, Eur. J. Inorg. Chem. 2007, 5548-5555.

[45] K. Shimada, A. Kobayashi, Y. Ono, H. Ohara, T. Hasegawa, T. Taketsugu, E. Sakuda, S. Akagi, N. Kitamura, M. Kato, J. Phys. Chem. C 2016, 120, 16002-16011.

[46] M. Schmittel, B. He, P. Mal, Org, Lett. 2008, 10, 2513-2516.

[47] A. Pun, D. A. Hanifi, G. Kiel, E. O'Brien, Y. Liu, Angew. Chem. Int. Ed. 2012, 51, 13119-13122.

[48] H. Yersin, A. F. Rausch, R. Czerwieniec, T. Hofbeck, T. Fischer, Coord. Chem. Rev. 2011, 255, 2622-2652.

[49] S. Shibata, K. Tsuge, Y. Sasaki, S. Ishizaka, N. Kitamura, Inorg. Chem. 2015, 54, 9733-9739.

[50] CrystalClear; Molecular Structure Corporation: Orem, UT, 2001.

[51] CrysAlisPro, version 1.171.39.45h; Rigaku Corporation, Oxford, UK 2018

[52] SHELX: G. M. Sheldrick, Acta Crystallogr. 2008, A64, 112.

[53] CrystalStructure 4.1, Crystal Structure Analysis Package; Rigaku Corporation: Tokyo, 2000-2014.

[54] Olex2: O. V. Dolomanov, L. J. Bourhis, R. J. Gildea, J. A. K. Howard, H. Pushmann, J. Appl. Cryst. 2009, 42, 339.

[55] Gaussian 09, Revision E.01, M. J. Frisch, G. W. Trucks, H. B. Schlegel G. E. Scuseria, M. A. Robb, J. R. Cheeseman, G. Scalmani, V. Barone B. Mennucci, G. A. Petersson, H. Nakatsuji, M. Caricato, X. Li, H. P Hratchian, A. F. Izmaylov, J. Bloino, G. Zheng, J. L. Sonnenberg, M. Hada, M. Ehara, K. Toyota, R. Fukuda, J. Hasegawa, M. Ishida, T. Nakajima, Y. Honda, O. Kitao, H. Nakai, T. Vreven, J. A. Montgomery, Jr., J. E. Peralta, F. Ogliaro, M. Bearpark, J. J. Heyd, E. Brothers, K. N Kudin, V. N. Staroverov, R. Kobayashi, J. Normand, K. Raghavachari, A. Rendell, J. C. Burant, S. S. Iyengar, J. Tomasi, M. Cossi, N. Rega, J. 
M. Millam, M. Klene, J. E. Knox, J. B. Cross, V. Bakken, C. Adamo, J. Jaramillo, R. Gomperts, R. E. Stratmann, O. Yazyev, A. J. Austin, R. Cammi, C. Pomelli, J. W. Ochterski, R. L. Martin, K. Morokuma, V. G. Zakrzewski, G. A. Voth, P. Salvador, J. J. Dannenberg, S. Dapprich, A. D. Daniels, Ö. Farkas, J. B. Foresman, J. V. Ortiz, J. Cioslowski, D. J. Fox, Gaussian, Inc., Wallingford CT, 2009

[56] A. D. Becke, J. Chem. Phys. 1993, 98, 5648-5652.

[57] C. Lee, W. Yang, R. G. Parr, Phys. Rev. B: Condens. Matter Mater. Phys. 1988, 37, 785-789.
[58] W. J. Hehre, R. Ditchfield, J. A. Pople, J. Chem. Phys. 1972, 56 2257-2261

[59] M. M. Francl, W. J. Petro, W. J. Hehre, J. S. Binkley, M. S. Gordon, D. J. Defrees, J. A. Pople, J. Chem. Phys. 1982, 77, 3654-3665.

[60] D. Andrae, U. Haussermann, M. Dolg, H. Stoll, H. Preuss, Theor. Chem. Acta. 1990, 77, 123-141.

[61] W. Küechle, M. Dolg, H. Stoll, H. Preuss, J. Chem. Phys. 1994, 100, 7535-7542. 


\section{Entry for the Table of Contents}

Layout 1:

\section{FULL PAPER}

Unique mechanochromic switching between thermally activated delayed fluorescence and phosphorescence of newly synthesized luminescent $\mathrm{Cu}(\mathrm{I})$ coordination polymers,

$\left[\mathrm{Cu}_{2} \mathrm{I}_{2}\left(\mathrm{PPh}_{3}\right)_{2}(m \text {-tpyb })\right]_{\mathrm{n}}\left(\mathrm{PPh}_{3}=\right.$

triphenylphosphine, $m$-tpyb $=1,3,5$ tris ( $m$-pyridyl)benzene; $m=3,4$ ) has been described.
Mechanochromic switching of two emissive states

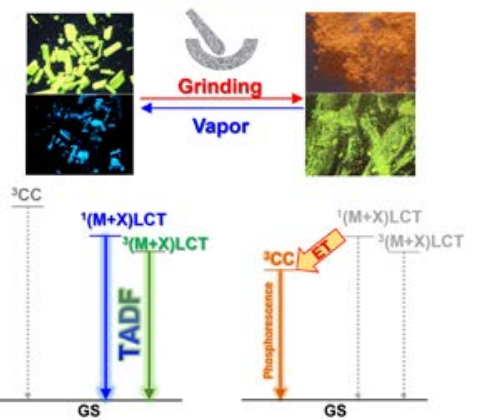

Atsushi Kobayashi*, Yuya Yoshida, Masaki Yoshida, and Masako Kato*

Page No. - Page No.

Mechanochromic Switching between Delayed Fluorescence and Phosphorescence of Luminescent Coordination Polymers Composed of Dinuclear Copper(I) lodide Rhombic Cores 